\title{
Environmental influences on the intensity changes of tropical cyclones over the western North Pacific
}

\author{
Shoujuan Shu ${ }^{1}$, Fuqing Zhang ${ }^{2}$, Jie Ming ${ }^{1}$, and Yuan Wang ${ }^{1}$ \\ ${ }^{1}$ Key Laboratory of Mesoscale Severe Weather of Ministry of Education, School of Atmospheric Sciences, Nanjing \\ University, Nanjing, China \\ ${ }^{2}$ Department of Meteorology, The Pennsylvania State University, University Park, Pennsylvania, USA
}

Correspondence to: S. Shu (sjshu@nju.edu.cn)

Received: 11 August 2013 - Published in Atmos. Chem. Phys. Discuss.: 4 December 2013

Revised: 12 April 2014 - Accepted: 19 May 2014 - Published: 25 June 2014

\begin{abstract}
The influence of environmental conditions on the intensity changes of tropical cyclones (TCs) over the western North Pacific (WNP) is investigated through examination of 37 TCs during 2000-2011 that interacted directly with the western North Pacific subtropical high (WNPSH). Comprehensive composite analysis of the environmental conditions is performed for two stages of storms: one is categorized as intensifying events (maximum wind speed increases by $15 \mathrm{kn}$ over $48 \mathrm{~h}$ ) and the other is categorized as weakening events (maximum wind speed decreases by $15 \mathrm{kn}$ over $48 \mathrm{~h}$ ). Comparison of the composite analysis of these two cases show that environmental conditions associated with the WNPSH play important roles in the intensity changes of TCs over the WNP. When a TC moves along the southern periphery of the WNPSH, the relatively weaker easterly environmental vertical wind shear helps bring warm moist air from the south and southeast to its southeast quadrant within $500 \mathrm{~km}$, which is favorable for the TC to intensify. However, when a TC moves along the western edge of the WNPSH, under the combined influences of the WNPSH and an upper-level westerly trough, a strong westerly vertical shear promotes the intrusion of dry environmental air associated with the WNPSH from the north and northwest, which may lead to the inhibition of moisture supply and convection over the western half of the TC and thus its weakening. These composite results are consistent with those with additional geographic restrictions, suggesting that the dry air intrusion and the vertical wind shear (VWS) associated with the WNPSH, indeed affect the intensity changes of TCs over the WNP beyond the difference related solely to variations in geographical locations. The average sea surface temperature (SST) of $27.6^{\circ} \mathrm{C}$
\end{abstract}

for the weakening events is also lower than an average of $28.9^{\circ} \mathrm{C}$ for the strengthening events, but remains above the critical value of $27^{\circ} \mathrm{C}$ for TC intensification, suggesting that the SST may be regarded as a less positive factor for the weakening events.

\section{Introduction}

For the past few decades, despite large improvement in the track forecast of tropical cyclones (TCs), there has been almost no improvement in the intensity forecast for all lead times (Cangialosi and Franklin, 2012). This is, in part, attributed to our limited understanding of the physical mechanisms that are responsible for the changes of TC intensity (e.g., Emanuel, 2000; Wang and Wu, 2004), and both the practical and intrinsic predictability under the current generation of numerical models and observing networks for the TCs (e.g., Zhang and Sippel, 2009; Zhang et al., 2011).

The ocean has long been recognized as having a fundamental impact on TC intensity (Byers, 1944; Miller, 1958; Malkus and Riehl, 1960). Palmén (1948) found that TCs in the Northern Hemisphere formed over oceans with sea surface temperature (SST) higher than $26-27^{\circ} \mathrm{C}$. Chan et al. (2001) also showed that a critical, warm SST of about $27^{\circ} \mathrm{C}$ was necessary for a TC to intensify. SST determines the amount of sensible and latent heat available to the TC from the underlying ocean and, thus, is indicative of the potential TC intensity (Miller, 1958; Malkus and Riehl, 1960). So, many maximum potential intensity (MPI) theories (Merrill, 1988; Emanuel, 1986, 1988, 1991, 1995; Holland, 1997; 
Zeng et al., 2007) have been derived to take into account the positive impact of warm SST on TC development.

Though most studies focused on the contributing aspects of the ocean on TC intensity, observational (Black, 1983) and modeling studies (Sutyrin and Khain, 1979; Bender et al., 1993; Bender and Ginis, 2000) have shown that upwelling and vertical mixing of the cooler water underneath the ocean surface by the TC vortex can produce a negative feedback to TC intensity. However, some studies (Shay et al., 2000; Hong et al., 2000; Cione and Uhlhorn, 2003; Mainelli et al., 2008) suggest that warm ocean eddies may reduce storm-induced negative feedback.

The importance of large-scale environmental forcing on TC intensity change has also been stressed. Through cloudresolving simulations, Fang and Zhang (2012) examined the effect of $\beta$ on the evolution of TCs and found that the TC simulated on a $\beta$ plane with variable Coriolis parameter $f$ is weaker in intensity but larger in size than the TC simulated on an $f$ plane with constant $f$. The vertical wind shear has long been recognized as a key detrimental factor affecting TC intensity. Gray (1968) and Merrill (1988) showed that the intensifying TCs tended to have lower vertical shear than the non-intensifying ones. Modeling results conducted by Frank and Ritchie $(1999,2001)$ indicated that a low vertical wind shear could result in rapid intensification of a TC. An early explanation of the impact of vertical shear is the so-called "ventilation" effect (Simpson and Riehl, 1958); namely, advective horizontal displacement of the warm core by flow in the upper levels relative to the low-level TC circulation. An alternative manifestation of the ventilation effect is the outward eddy flux of warm core air by the shear-induced asymmetric flow in the upper levels, causing a decrease of the warm core from top to bottom and thus weakening the TC (Frank and Ritchie, 2001). An alternative hypothesis was recently presented in Riemer et al. $(2010,2013)$ : the cooler and drier (lower $\theta e$ ) air could be brought into the boundary layer from above by shear-induced downdrafts flux, which significantly reduces eyewall $\theta e$ values and subsequently constrains the storm intensity when the lower $\theta e$ air enters the eyewall updrafts. Riemer and Montgomery (2011) further argued that the environmental vertical wind shear might promote or impede the interaction with the environmental air depending on the direction of the shear vector. They noted that a vortex embedded in a mean flow has a protective kinematic boundary (separatrix) whose orientation and hyperbolic saddle point vary with height in a vertically sheared flow. They also suggested that it is not only the dynamic resiliency of a TC that increases with intensity (Reasor et al., 2004); the ability of a TC to isolate itself from adverse thermodynamic interaction with environmental air also increases with intensity. The recent study of Stern and Zhang (2013) also found that the final intensity of a TC (and warm core height) are relatively insensitive to the presence of up to $10 \mathrm{~m} \mathrm{~s}^{-1}$ of vertical wind shear although stirring in the eye-eyewall interface region is substantially enhanced by shear. Moreover, the impact of vertical wind shear on the TC intensity is not only an issue of theoretical interest but also of great relevance to the practical intensity forecast of a TC. As noted by Emanuel et al. (2004), the greatest source of uncertainty in forecasts of TC intensity may be due to the uncertainty in forecasts of the environmental vertical shear. Zhang and Tao (2013) further demonstrated that the larger the shear, the intrinsically less predictable the tropical cyclones.

Besides environmental vertical wind shear, an upper-level trough associated with midlatitude systems may impose a cyclonic PV (potential vorticity) anomaly and sometimes may contribute to TC intensity changes (Titley and Elsberry, 2000). For example, Hanley et al. (2001) found that a larger and stronger upper trough induces more vertical shear than a small-scale trough, and has a negative impact on the TC intensity.

Over the Atlantic Ocean, early studies (e.g., Karyampudi and Carlson, 1988; Karyampudi and Pierce, 2002) suggested a potential positive influence of the Saharan air layer (SAL) on the growth of TCs, while many recent studies (Dunion and Velden, 2004; Lau and Kim, 2007a, b; Sun et al., 2008; Evan et al., 2006; Wu, 2007; Shu and Wu, 2009) suggested that the SAL has a negative impact. However, there are few studies examining the impact of dry environmental air on TCs over the western North Pacific (WNP). Dry air is also prevalent over the WNP oceanic regions as the product of the climatological subtropical high-pressure system (Braun, 2010), whose impact on TC intensity changes will be the subject of the current study.

Based on the observations, a new empirical MPI has been developed for TCs over the WNP in a recent study by Zeng et al. (2007), which considers not only the positive contributions of SST and the effect of the thermodynamic efficiency but also the combined negative effect of translational speed and environmental vertical shear. They found that although the new empirical MPI with consideration of negative effects provides a relatively accurate estimation of TC maximum intensity, a large portion of TCs still could not reach their MPIs even in favorable environmental conditions, which indicates that other factors like dry air intrusion and the direction of environmental vertical wind shear vector should also be taken into account in developing MPIs for TCs over the WNP.

As the most active basin for TC genesis, the WNP has a favorable environment with warm SST and high relative humidity (e.g., Gray, 1968; McBride, 1995). In addition, a climatological weather system - the western North Pacific subtropical high (WNPSH) affects East Asia during the highly active TC season from July to September over the WNP. Many studies have been carried out on the relations between the WNPSH and TCs over the past decade. For example, the size of a TC is potentially affected by the synoptic patterns associated with the dominant subtropical high (Liu and Chan, 2002; Chan and Chan, 2012). Lee et al. (2010) found that small TCs are more influenced by the WNPSH during their intensification due to the increased environmental 

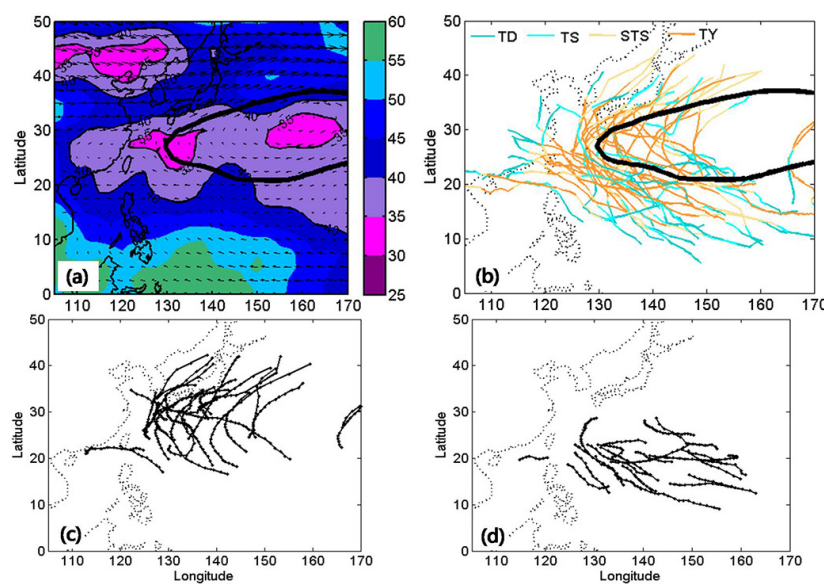

Figure 1. September 2004-2009 mean GFS-derived (a) 500$400 \mathrm{hPa}$ layer RH (shading) and flow vectors, (b) geopotential height of $5880 \mathrm{~m}$ at $500 \mathrm{hPa}$ (thick black line) which is also plotted in (a) and all tracks of TCs with colorized lines indicating storm intensity, (c) weakening cases and (d) strengthening cases during the $48 \mathrm{~h}$ period used to classify them. Black contours are drawn at 40 and $35 \% \mathrm{RH}$ in (a).

average wind speed in the north of the TC caused by a tighter pressure gradient between the cyclone and the subtropical high. On the interdecadal timescale, a weakening in vertical wind shear, or eastward retreating of the WNPSH, sets up favorable environments for more TC formations in the Philippine Sea (e.g., Lander, 1994; Harr and Elsberry, 1995; Chan, 2000; Chen and Chen, 2011). Moreover, TCs are often steered by strong trade easterlies along the southern periphery of the WNPSH with westward-moving tracks, or recurve during strong monsoon westerlies over the WNP (Chen et al., 2009). As Fu et al. (2012) noted, the background climatology in the WNP is different from that in the North Atlantic Basin. Unlike the Atlantic, where easterly trades and the subtropical high occupy the majority of tropical basins, the easterlies and southwesterlies associated with the WNPSH (and also the western Pacific monsoon) are important components of the summertime circulation in the WNP (their Fig. 1). A recent study by Shu et al. (2012) also showed that the intensifying events usually have more easterly upper-tropospheric flow than the nonintensifying events, suggesting a possible role of the WNPSH for the former. Since whether and how the WNPSH influences TC intensity has not been obtained, the potential impacts of environmental parameters associated with the WNPSH were not taken into account in developing MPI in Zeng et al. (2007). This may partly explain why most TCs could not reach their MPIs even in the favorable environment in their study.

The objective of this study is to investigate observationally whether and how the environmental conditions associated with the WNPSH may influence the intensity changes of TCs over the WNP, in an effort to provide further guid- ance to the practical TC intensity forecasts over the WNP. The paper is organized as follows. Section 2 describes the data and methods used for the analysis. Section 3 provides a climatological context for the WNPSH by examining the mean properties of the WNPSH and its environment over the WNP. Section 4 describes composite analyses and possible mechanisms for both strengthening and weakening events. Concluding remarks are presented in Sect. 5 .

\section{Data and methodology}

\subsection{Best track estimates, global analyses and satellite data used}

Tropical cyclone data over the WNP during the period 2000-2011 were obtained from JMA (Japan Meteorological Agency). The tropical cyclone best track data include the center latitude and longitude, and the maximum sustained winds for each $6 \mathrm{~h}$ interval. The Atmospheric Infrared Sounder (AIRS) and Advanced Microwave Sounding Unit (AMSU) data from the Aqua satellite are used to retrieve humidity profiles that are essential to characterize the thermodynamic properties of the atmosphere. The AIRS-AMSU level-3 monthly mean standard product is used in this paper. In addition, since satellite data provide limited wind information, the NCEP (National Centers for Environmental Prediction) Global Forecasting System (GFS) final global analyses with a horizontal resolution of $1^{\circ} \times 1^{\circ}$, available every $6 \mathrm{~h}$, are used to characterize the kinematic properties of tropical cyclones and environmental conditions. The SST data used are Reynolds SST reanalysis provided by the National Oceanic and Atmospheric Administration (NOAA) Cooperative Institute for Research in Environmental Science (CIRES) Climate Diagnostics Center (CDC), which can be obtained online at http://www.cdc.noaa.gov. The Reynolds SST is a weekly mean with a horizontal resolution of $1^{\circ} \times 1^{\circ}$ (Reynolds et al., 2002).

\subsection{Categorization and compositing methods for intensifying vs. weakening TC events}

Over the WNP, the subtropical high usually moves poleward and extends westward from the central Pacific to eastern China in June-July, and moves equatorward and retreats eastward during September-October (Fig. 11 in Chan and Chan, 2012). In order to highlight the impact of the WNPSH, which is normally the strongest and covers the largest area during July-September, TCs were selected based on the following criteria. Firstly, only those formed in the months JulySeptember during 2000-2011 over the WNP are sampled. Secondly, in order to ensure a more likely interaction between the WNPSH and TCs, the closest distance between the center of a TC and the isoline of $5880 \mathrm{gpm}$ (geopotential meter) on the $500 \mathrm{hPa}$ geopotential height was less than $800 \mathrm{~km}$, since $500 \mathrm{hPa}$ is the characteristic level of the WNPSH over 
the WNP (Chan et al., 2001). Also, the closest distance between the center of a TC and the isoline of $40 \%$ relative humidity (RH) associated with the WNPSH was less than $800 \mathrm{~km}$ at $500 \mathrm{hPa}$. Finally, this "interaction" pattern lasted more than $48 \mathrm{~h}$. For simplicity, we call a TC that satisfies these criteria as the one "interacting" with the WNPSH. TCs that weaken in the next $48 \mathrm{~h}$ owing to landfall or whose life span is shorter than $48 \mathrm{~h}$ were both excluded in the sampled cases. After a careful analysis of the synoptic weather maps in GFS analyses, as well as the AIRS-AMSU satellite data, 37 TCs consisting of 1472 sample times which constitute about $56.4 \%$ of all 60 TCs selected from 2000 to 2011 are examined in this paper. The tracks of all the TCs to be examined in this study are shown in Fig. 1b.

An intensifying (weakening) event was identified if the TC increased (decreased) in intensity by at least $15 \mathrm{kn}$ within the next $48 \mathrm{~h}$. Note that despite the disagreement between different TC best track data sets, the use of $48 \mathrm{~h}$ intensity increments in the maximum-sustained wind speed has greatly diminished the inconsistencies of the data sets. Among the total 1472 samples of 37 TC events over the 12-year period, 274 samples from 26 TCs and 386 samples from 27 TCs were grouped into the intensifying and weakening events, respectively.

Composite fields were obtained for the time (designated as $t_{0 \mathrm{~h}}$ ) when the TC met the above criteria for intensifying or weakening. The reference time $t_{0 \mathrm{~h}}$ falls at the start in the $48 \mathrm{~h}$ interval during which the storm was weakening or intensifying. Composite fields were also computed for time $t_{+24 \mathrm{~h}}$ through $t_{+48} \mathrm{~h}$ as well as $t_{-12 \mathrm{~h}}$, where the subscript indicates the time, in hours, relative to $t_{0 \mathrm{~h}}$, and the plus and the minus signs show the hours after and prior to $t_{0 \mathrm{~h}}$, respectively. If a storm position at $t_{+48}$ was not available in the JMA best track data, it was excluded from the composite for that time. For each storm and each time, the environmental fields were obtained for a $40^{\circ}$ latitude by $40^{\circ}$ longitude box centered on the storm. The composite fields were obtained by arithmetic average over those $40^{\circ} \times 40^{\circ}$ TC-centered boxes at different times (from $t_{-12 \mathrm{~h}}$ to $t_{+48 \mathrm{~h}}$ ).

\section{Overview of the WNPSH during the WNP typhoon season}

AIRS-AMSU derived satellite observations and GFS analyses are used here to characterize the large-scale environmental conditions and the WNPSH during the WNP typhoon season. In the current study, the geopotential height of $5880 \mathrm{~m}$ at $500 \mathrm{hPa}$ is used to represent the position of the WNPSH. Taking September as a typical WNP TC season month for example, Fig. 1a shows the mean circulation and RH associated with the WNPSH from the GFS analyses at $500 \mathrm{hPa}$ averaged over the period 2004-2009. The anticyclonic circulation associated with the WNPSH dominates a large area of the WNP, with relatively stronger westerly flow on its north-
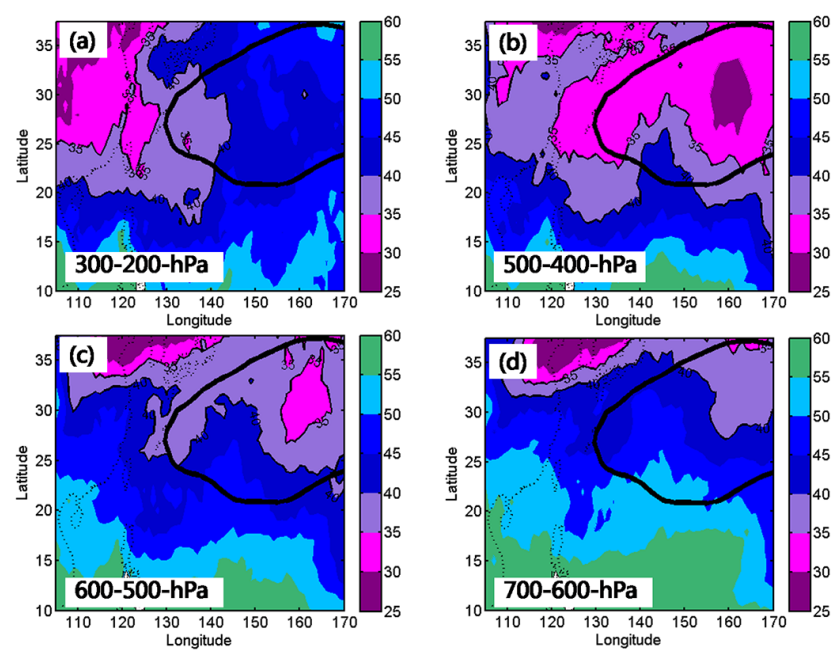

Figure 2. September 2004-2009 mean AIRS-AMSU-derived RHs (shading) in (a) $300-200 \mathrm{hPa}$, (b) $500-400 \mathrm{hPa}$, (c) $600-500 \mathrm{hPa}$, and (d) $700-600 \mathrm{hPa}$ layers, respectively. Black contours are drawn at 40 and $35 \% \mathrm{RH}$ in each panel. The thick black line is the mean GFS-derived geopotential height of $5880 \mathrm{~m}$ at $500 \mathrm{hPa}$.

ern periphery than the reverse flow on its southern periphery. Overall, the WNPSH area is basically a large zonal region of dry air $(\mathrm{RH}<=40 \%)$ with the driest region having $\mathrm{RH}$ as low or less than $35 \%$ over the center of the high pressure and the western part of the WNPSH. Figure 1b shows the tracks of all the TCs to be examined over the WNP in this study. Most TCs passed the western edge of the WNPSH where the $\mathrm{RH}$ is very low during their lifetime, suggesting that the dry air associated with the WNPSH may interact with the TCs.

Figure 2 shows the mean RH associated with the WNPSH at different levels derived from the AIRS-AMSU data averaged over September of 2004-2009. For the midtroposphere, the very dry air $(\mathrm{RH} \leq 35 \%)$ almost dominates the entire WHPSH area in the 500-400 hPa layer except for maybe the southern edge (Fig. 2b). The same is true in the $600-$ $500 \mathrm{hPa}$ layer though to a slightly lesser extent (Fig. 2c). However, in the upper troposphere above $300 \mathrm{hPa}$, the dry air is mostly prevalent over the western edge of the WNPSH (Fig. 2a) while in the lower troposphere below $600 \mathrm{hPa}$ it is mostly prevalent over the northern peripheries of the WNPSH (Fig. 2d). Thus, the direct drying by large-scale subsidence associated with the WNPSH is evidenced primarily at the midtropospheric level (Fig. 2b, c). During the TC season in which the WNPSH gradually strengthens and shifts westward from July to September over the WNP, so does the area of accompanying subsiding dry air.

The RH field derived from the GFS analyses (Fig. 1a) can not be compared directly with that derived from the AIRSAMSU satellite observation (Fig. 2b) since the latter measures the mean RH of the layer. However, the mean RH field averaged in the $500-400 \mathrm{hPa}$ is nearly identical to Fig. 1a, 

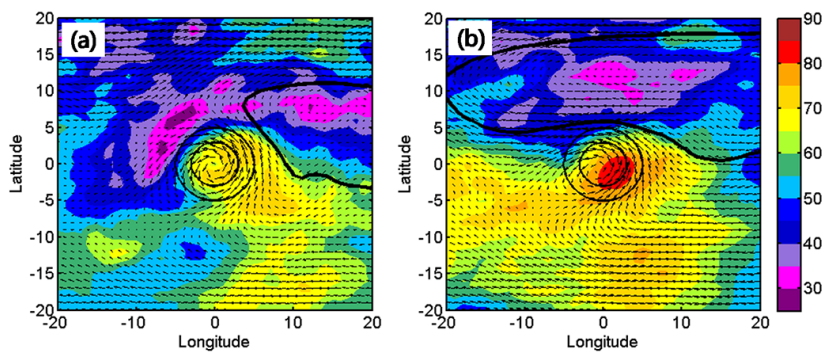

Figure 3. GFS-derived fields for the composites of RH (shading, $5 \%$ intervals starting at $25 \%$ ), vector winds at $400 \mathrm{hPa}$, and geopotential height of $5880 \mathrm{~m}$ at $500 \mathrm{hPa}$ (thick black line) for (left) weakening and (right) strengthening events at time $t_{-12 \mathrm{~h}}$. The two black solid circles are $3^{\circ}$ - and $5^{\circ}$-radius circles centered on the storm.

except that the air is somewhat drier over the northern edge of the WNPSH in the satellite data.

\section{Composite analysis of environmental conditions: intensifying vs. weakening events}

\subsection{Relative humidity}

Due to relatively low-horizontal $\left(1^{\circ} \times 1^{\circ}\right)$ resolution of the GFS FNL data as well as limited availability of inner-core observations being assimilated into GFS, some structures within the eyewall or near-core region cannot be well depicted. We hereby loosely define the area with a radius of $400 \mathrm{~km}$ from the TC center as the inner-core region of a TC, and the broader area of cyclonic circulation as the "TC circulation". Figure 3 shows composites of $400 \mathrm{hPa}$ mean $\mathrm{RH}$ for both the weakening and the intensifying events at time $t_{-12 \mathrm{~h}}$, where $t_{-12 \mathrm{~h}}$ means $12 \mathrm{~h}$ prior to $t_{0 \mathrm{~h}}$. For the weakening cases (Fig. 3a), the TC is on average located at the southwestern/westernedge of the "composite WNPSH". Note that the WNPSH here is not exactly the same with those in Figs. 1 and 2 , since the former is a representation of the subtropical high as seen in the storm-relative composite and the latter represent the climatological feature in an Earth-relative frame, as follows. The cyclonic circulation of the TC drives the dry air originating in the western tip of the WNPSH southward to the northwest of the TC. But for the strengthening cases (Fig. 3b), the TC is on average situated to the southern edge of the WNPSH. The easterlies are strong in the region between the WNPSH and the TC due to the strong meridional pressure gradient. The dry air associated with the WNPSH is further north and does not seem to have a direct impact on the TC at this stage.

Figure 4 shows the composite of $\mathrm{RH}$ at $500 \mathrm{hPa}$ for both the weakening and the intensifying events at time $t_{0 \mathrm{~h}}$, respectively. The composite fields at $400 \mathrm{hPa}$ for the two cases are very similar to those at $500 \mathrm{hPa}$ (not shown). For the weakening cases (Fig. 4a), the TC is on average reaching the western edge of the WNPSH. At both levels, the WNPSH dry air
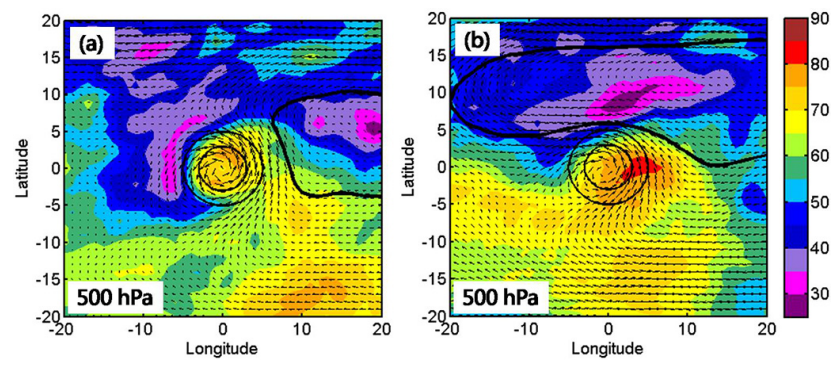

Figure 4. GFS-derived fields for the composites of RH (shading, $5 \%$ intervals starting at $25 \%$ ), vector winds and geopotential height of $5880 \mathrm{~m}$ at $500 \mathrm{hPa}$ (thick black line) at $500 \mathrm{hPa}$ for (left) weakening and (right) strengthening events at time $t_{0 \mathrm{~h}}$. The two black solid circles are $3^{\circ}$ - and $5^{\circ}$-radius circles centered on the storm.

with RH as low as $40 \%$ extends further southward and intrudes into the western part of the TC within $500 \mathrm{~km}$ of the cyclonic circulation. The leading edge of this dry air also begins to wrap into the TC circulation from the southwest to the south quadrant. For the strengthening cases (Fig. 4b), the TC moves continuously westward along the southern edge of the WNPSH. At both 400 (not shown) and $500 \mathrm{hPa}$ (Fig. 4b), the dry area with $\mathrm{RH}$ as low as $40 \%$ extends somewhat southward, closer to the TC circulation than at $-12 \mathrm{~h}$, but overall the TC is situated in an area with relatively large RH, especially to the south and east sides of the TC circulation. The difference in the composite RH between the weakening and intensifying cases is also clear in the lower troposphere (700 hPa; Fig. 5), with drier air closer to the weakening TC circulation on its northwest side while abundant moisture exists to the southeast side for the strengthening cases. Comparisons of the RH fields in Figs. 4 and 5 at $t_{0 \mathrm{~h}}$ (as well as in Figs. 6 and 7 of later times) suggest that the dry air associated with the WNPSH extending southward to the west of the storm may have played a negative role in TC development for the weakening events while the warm moist air to the southeast of the TC circulation may have promoted intensification of the TC for the strengthening events. In other words, different environmental flow conditions associated with the difference in the position of the TC relative to the WNPSH may have played a role in the weakening/intensifying TCs (details later). This is to a certain extent consistent with the idealized study of Riemer and Montgomery (2011), who showed that if the sheared flow favors the interaction with dry air masses, a more pronounced weakening of the TC can be expected in comparison to a shear direction that favors interaction with relatively moist environmental air.

Figure 6 shows the composites of mean $500 \mathrm{hPa}$ RH for both the weakening and the intensifying events at time $t_{+24 \mathrm{~h}}$. Overall, the positioning of the TC with respect to the WNPSH, and the moisture pattern with respect to the TC circulation in the midtroposphere remain largely unchanged for the weakening events at $t_{+24 \mathrm{~h}}$ (Fig. 6a) compared to $t_{0 \mathrm{~h}}$ (Fig. 4a). Even though the dry air in the southwestern side 

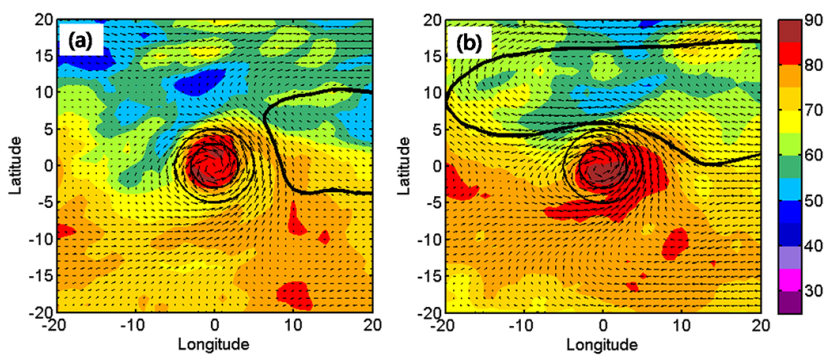

Figure 5. As in Fig. 4 but at $700 \mathrm{hPa}$.
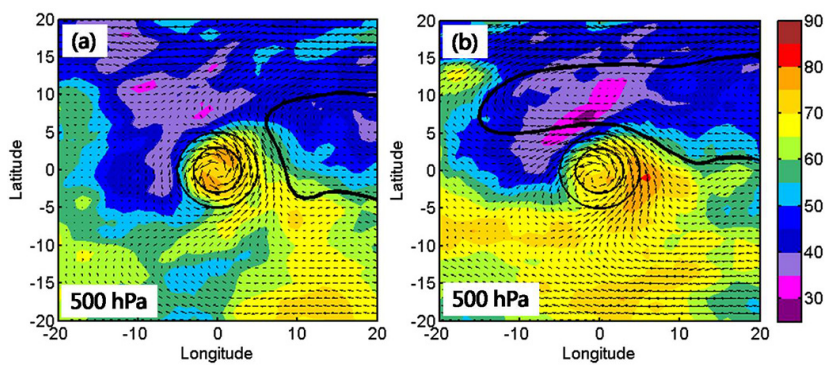

Figure 6. As in Fig. 4 but at time $t_{+24 \mathrm{~h}}$.

of the TC may be somewhat closer to the TC center during the long weakening stage, the moisture content within the primary TC circulation remains high at $t_{+24 \mathrm{~h}}$. More evident changes in midtropospheric moisture are seen in the composites for the strengthening cases at $t_{+24 \mathrm{~h}}$ (Fig. 6b). With the TC moving further westward and intensifying, there is some indication that the cyclonic TC circulation may have begun to bring some of the dry air associated the WNPSH closer to the TC to the northwest at $t_{+24 \mathrm{~h}}$ (Fig. 6b).

Figure 7 shows the composites of RH at $500 \mathrm{hPa}$ for both the weakening and the intensifying stages at $t_{+48 \mathrm{~h}}$. For the weakening cases (Fig. 7a), more dry air is located within a $500 \mathrm{~km}$ radius of the TC with the cyclonic flow. The dry-air boundary $(\mathrm{RH} \leq 40 \%)$ comes closer to the TC circulation than a day before, especially in the southwest quadrant of the TC. The inward intrusion of the dry air also prevents the moist air from entering into the vortex circulation over the southwestern side of the storm. For the strengthening cases (Fig. 7b), the dry air associated with the WNPSH also extends further from the north to the southwest side of the TC circulation, though to a much lesser extent than that for the weakening events. On an even broader scale, the midtropospheric dry air is present in nearly three quadrants (from east to north to west) of the TC circulation for the weakening events but only in about two quadrants (north and west) for the strengthening events.

Figure 8 shows the composites of mean $500 \mathrm{hPa}$ vertical velocity and $700 \mathrm{hPa} \mathrm{RH}$ for both the weakening and the intensifying events at time $t_{+48 \mathrm{~h}}$. In both cases, the dry area ( $\mathrm{RH} \leq 40 \%$ ) corresponds well with the region of subsidence in the midtroposphere. For the weakening cases (Fig. 8a, c),
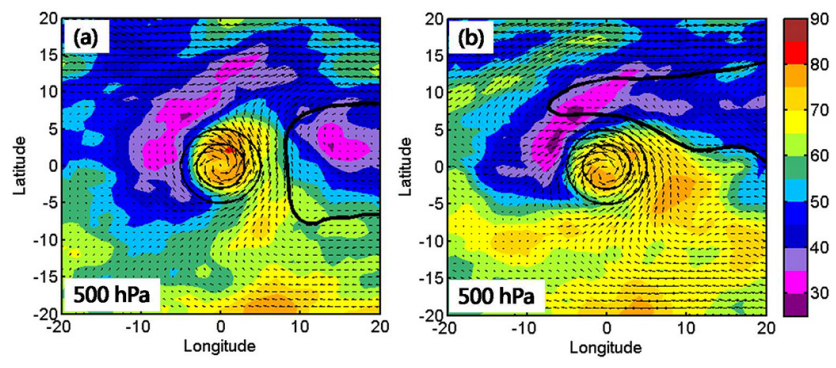

Figure 7. As in Fig. 4 but at time $t_{+48 \mathrm{~h}}$.
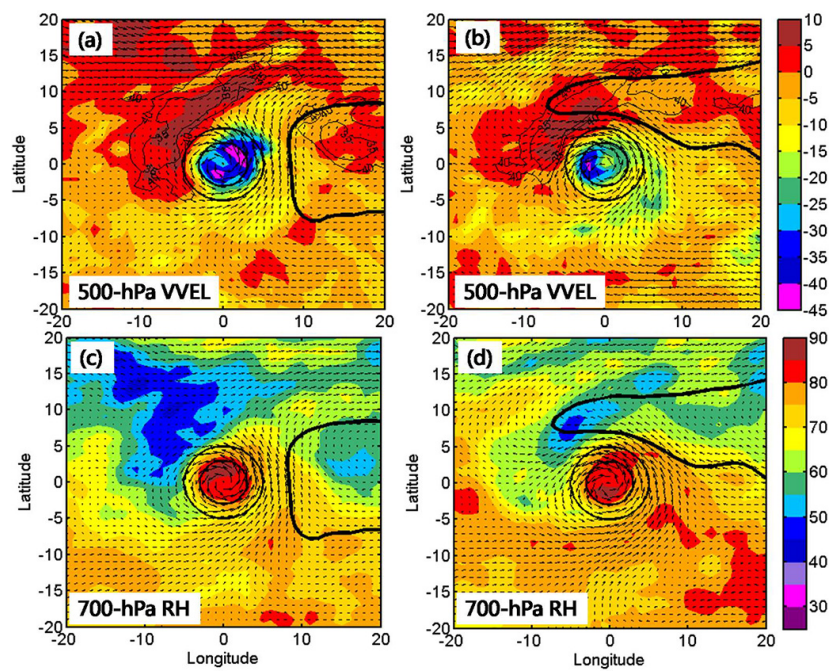

Figure 8. GFS-derived fields for the composites of vector winds and geopotential height of $5880 \mathrm{~m}$ at $500 \mathrm{hPa}$ (thick black line) and (top) the $500 \mathrm{hPa}$ vertical velocity fields (in $\mathrm{hPa} \mathrm{s}^{-1}$, shading) and (bottom) the $700 \mathrm{hPa} \mathrm{RH}$ (shading) for (left) weakening and (right) strengthening events at time $t_{+48 \mathrm{~h}}$. Black contours are drawn at 40 and $35 \% 500 \mathrm{hPa} \mathrm{RH}$ in the top panels. The two black solid circles are $3^{\circ}$ - and $5^{\circ}$-radius circles centered on the storm.

the subsidence occurs over the northwest and west quadrants including those within the $500 \mathrm{~km}$ radius of the TC. The subsiding dry air leads to persistent drying in the lower troposphere $(\mathrm{RH} \leq 65 \%)$ at $700 \mathrm{hPa}$, which may lead to the weakening of the TC. But for the strengthening cases (Fig. 8b, d), the midtropospheric dry subsidence mainly occurs to the northwest beyond $600 \mathrm{~km}$ from the TC center. However, much stronger ascending moister air in the southeast quadrant is seen to feed into the strengthening TC circulation.

In summary, although it is hard to assign causality conclusively, it appears that the more extensive midlevel intruding dry air may have contributed greatly to the weakening events, while for the strengthening events, the TC is mostly shielded from the dry air effects (besides having stronger moisture supply from the southeast side). Next we will examine other environmental factors that may have contributed to the dry intrusion, weakening or the strengthening of the TC events. 


\subsection{Vertical wind shear}

The mean environmental vertical wind shear of the storm is calculated following the methodology of Hanley et al. (2001). The zonal and meridional velocity components are interpolated onto an azimuthal polar grid. The individual velocity components at the upper $(200 \mathrm{hPa})$ and lower levels $(850 \mathrm{hPa})$ are then area-averaged within a radius of $1000 \mathrm{~km}$ from the storm center. This method of averaging removes the symmetric vortex so that the winds provide a more appropriate measure of environmental flow across the storm. The commonly used deep layer vertical wind shear (VWS) between 200 and $850 \mathrm{hPa}$ is then calculated from the areaaveraged winds.

Table 1 shows the mean environmental VWS for both the weakening and the strengthening cases at different times. The differences of not only the magnitude but also the direction of the VWS between the two cases are statistically significant at the $95 \%$ confidence level from Student's $t$ test. On average, the easterly VWS of the intensifying cases is weaker than the westerly VWS of the weakening cases. This finding that the weakening cases corresponds to the stronger VWS, indicative of a negative effect of the vertical shear on TC intensity, is consistent with the prior result of Zeng et al. (2007). It is also possible that the vertical shear south of the WNPSH in intensifying cases may have promoted TC development owing to the ORR (oxygen reduction reaction) mechanism as shown by Dunkerton et al. (2009).

The more striking contrast from Table 1 is that the average direction of the VWS for the intensifying cases is significantly different to that for the weakening ones, with mostly easterly for the former and westerly for the latter. This finding strongly suggests that the adverse impact of the VWS on the TC intensification depends on the direction of the vertical shear and that the westerly VWS is likely to have more adverse effect on the TC intensity. This sensitivity to shear direction is to some extent consistent with the finding from the recent idealized study of Riemer and Montgomery (2011). The westerly VWS in the weakening cases is more conductive to bring abundant dry air in the northwest/west side of the TC (subsiding dry intrusion) to its southwestern quadrant.

Figure 9 shows the composites of geopotential height at $500 \mathrm{hPa}$ and spatial distributions of the VWS for both the weakening and the intensifying events at different times. Although there is no remarkable difference in the magnitude of the average environmental VWS between the two cases, the spatial distributions of the VWS for the two cases are very different. At time $t_{0 \mathrm{~h}}$, for the weakening cases (Fig. 9a), the region of the strong VWS $\left(\geq 10 \mathrm{~m} \mathrm{~s}^{-1}\right)$ is located in the north WNPSH-TC interaction area within a radius of $500 \mathrm{~km}$ from the TC center. But for the strengthening cases (Fig. 9b), such a VWS region does not exist within a radius of $1000 \mathrm{~km}$ from the TC center, and is well to the north. One day later, the VWS over the northern side of the TC becomes stronger and closer to the TC center than that at $t_{0 \mathrm{~h}}$ for the weakening cases (Fig. 9c), while for the strengthening cases (Fig. 9d), the VWS feature remains nearly the same as a day earlier. At time $t_{+48 \mathrm{~h}}$, the spatial differences of the shear between the two cases become more obvious. For the weakening cases (Fig. 9e), the strong VWS ( $\geq 10 \mathrm{~m} \mathrm{~s}^{-1}$ ) dominates the whole northern half of the TC circulation with the strongest VWS existing over the northeastern side of the TC, where the VWS is about $7.5 \mathrm{~m} \mathrm{~s}^{-1}$ stronger than that for the strengthening cases (Fig. 9f). Although it remains unknown how and whether the local strong vertical shear plays a role in the intensity change of a TC, we believe that the strong westerly VWS located in the north contributes to the stronger mean environmental VWS for the weakening cases (Table 1). The difference in the positions of TCs (relative to the WNPSH) seems to contribute to the different direction of the VWS between the intensifying and the weakening events, further analyses however show that the difference of composite VWS (magnitude and direction) between the two groups with additional geographic restriction is still similar to the above composite results, suggesting that the dry air intrusion and the VWS associated with the WNPSH indeed affect the intensity changes of TCs over the WNP.

Another striking characteristic in Fig. 9 is that the significant westerly VWS impacts the western and eastern sides of the TC with the shear becoming stronger for the weakening cases (Fig. 9c, e), in contrast to the easterly VWS for the strengthening cases (Fig. 9d, f). This result is further validated in Table 2, which shows the average zonal wind for the two cases at different times. From time $t_{+24 \mathrm{~h}}$ to $t_{+48 \mathrm{~h}}$, there are strong westerlies and nearly calm winds in the higher and lower levels respectively for the weakening cases while there are moderate and weak easterlies in the higher and lower levels respectively for the strengthening cases. Table 2 also shows that for the weakening cases, the average $200 \mathrm{hPa}$ zonal wind (U200) changes from a weaker easterly at time $t_{-12 \mathrm{~h}}$ to a relatively stronger westerly at later times. This finding suggests that the change of U200 to the westerly can serve as a good indication of the TC weakening for the operational intensity forecast of TCs.

Besides the WNPSH, the upper-level westerly trough may have also contributed to the relatively stronger westerly VWS for the weakening cases. Figure 10 shows the composites of geopotential height and RH at $200 \mathrm{hPa}$ for both the weakening and the intensifying events at time $t_{+48 \mathrm{~h}}$. For the weakening cases (Fig. 10a), a broad trough approaches and brings very strong westerlies to the northeast of the TC which, along with the interaction of the WNPSH (Fig. 9c, e), leads to the strong westerly VWS. Also, the upper-level westerly trough brings dry air from the high-latitude region, which extends southward and gathers with the WNPSH dry air into the northwestern side of the TC. As shown in Sect. 4.1, the subsiding dry air may lead to further drying of the TC in the mid- and lower troposphere. However, for the strengthening cases (Fig. 10b), the TC is located in the south of a ridge 
Table 1. The average environmental vertical wind shear between 200 and $850 \mathrm{hPa}$ for the intensifying and weakening cases at different times.

\begin{tabular}{lrr|rr|rr}
\hline & \multicolumn{2}{c|}{$t_{0 \mathrm{~h}}$} & \multicolumn{2}{|c|}{$t_{+24 \mathrm{~h}}$} & \multicolumn{2}{|c}{$t_{+48 \mathrm{~h}}$} \\
& $\mathrm{M}$ & $\mathrm{D}$ & $\mathrm{M}$ & $\mathrm{D})$ & $\mathrm{M}$ & $\mathrm{D}$ \\
& $(\mathrm{kn})$ & $\left(^{\circ}\right)$ & $(\mathrm{kn})$ & $\left(^{\circ}\right)$ & $(\mathrm{kn})$ & $\left(^{\circ}\right)$ \\
\hline intensifying & 14.1 & 68 & 14.7 & 67 & 15.1 & 70 \\
weakening & 17.1 & 275 & 18.7 & 279 & 20.3 & 281 \\
significant test at & $\mathrm{Y}$ & $\mathrm{Y}$ & $\mathrm{Y}$ & $\mathrm{Y}$ & $\mathrm{Y}$ & $\mathrm{Y}$ \\
$95 \%$ confidence level & & & & & & \\
\hline
\end{tabular}

* The symbols "M" and " $\mathrm{D}$ " indicate the magnitude and direction of the vertical wind shear, respectively. A wind coming from the south is given as $180^{\circ}$ and one from the east is $90^{\circ}$.
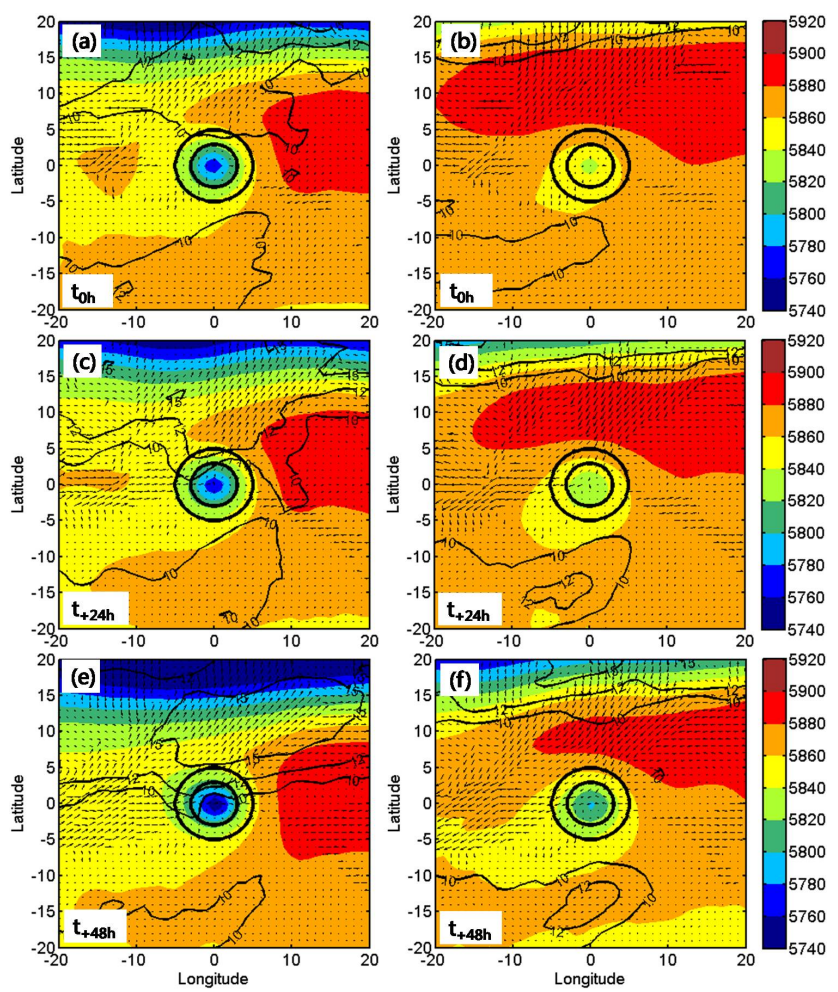

Figure 9. GFS-derived fields for the composites of the $500 \mathrm{hPa}$ geopotential height at 20 gpm intervals (shading), magnitude of the deep-layer vertical wind shear (contours, $2 \mathrm{~m} \mathrm{~s}^{-1}$ intervals starting at $10 \mathrm{~m} \mathrm{~s}^{-1}$ ) for (left) weakening and (right) strengthening events at time (top) $t_{0 \mathrm{~h}}$, (middle) $t_{+24 \mathrm{~h}}$ and (bottom) $t_{+48 \mathrm{~h}}$. Vectors in the left (right) panels mean the vector differences of the vertical wind shear between the weakening (strengthening) and the strengthening (weakening) cases, respectively. The two black solid circles are $3^{\circ}$ and $5^{\circ}$-radius circles centered on the storm.

which, together with the interaction of the WNPSH (Fig. 9b, d), leads to the easterly VWS over the far north of the TC.

Meanwhile, the environmental VWS induces a remarkable asymmetrical structure in the inner core region of the TC, with the strongest updraft (represented by the purple area) occurring in the downshear-left side in the inner core for both the weakening (Fig. 8a) and the strengthening cases (Fig. 8b).
Table 2. The average zonal wind $(U)$ for the weakening and intensifying cases at different times.

\begin{tabular}{lrr|rr}
\hline$U\left(\mathrm{~m} \mathrm{~s}^{-1}\right)$ & \multicolumn{2}{c|}{ weakening } & \multicolumn{2}{c}{ intensifying } \\
& $850 \mathrm{hPa}$ & $200 \mathrm{hPa}$ & $850 \mathrm{hPa}$ & $200 \mathrm{hPa}$ \\
\hline$t_{-12 \mathrm{~h}}$ & -1.0 & -0.3 & -1.3 & -2.2 \\
$t_{0 \mathrm{~h}}$ & -1.0 & 0.8 & -1.4 & -2.0 \\
$t_{+24 \mathrm{~h}}$ & 0.1 & 2.4 & -1.6 & -2.5 \\
$t_{+48 \mathrm{~h}}$ & 0.8 & 7.2 & -1.2 & -3.0 \\
\hline average & -0.3 & 2.5 & -1.4 & -2.4 \\
\hline
\end{tabular}

This observational result is also very consistent with many previous observational and numerical works (e.g., Reasor et al., 2013; Chan et al., 2004; Corbosiero and Molinari, 2003; Frank and Ritchie, 1999, 2001).

\subsection{Subsets of composites with similar geographic locations}

It is worth noting that the two cases of storms in the above composite analysis also have some systematic difference in geographic locations with respect to the WNPSH: the weakening storms are more likely to move along the western edge of the WNPSH, while for strengthening cases the storms are usually located in the southern periphery of the WNPSH. Differences in environmental VWS directions on the western vs. southern peripheries of the WNPSH may have also contributed to difference in the intensity changes of TCs for weakening vs. intensifying cases. In this section, we further subselect only the events located west of $135^{\circ} \mathrm{E}$, where the dry air associated with the WNPSH is evident for both the weakening and intensifying cases from the satellite images (Fig. 2). Even with this additional selection criteria, nearly half of the events from the original samples in each case group remained. Take the time $t_{+48 \mathrm{~h}}$ for example, about $46.2 \%(48.1 \%)$ of the original intensifying (weakening) cases are used further to do these additional composite analyses. All the remaining events with this subselection are now located to the west of the WNPSH while the averaged intensity for the weakening cases $\left(33.2 \mathrm{~m} \mathrm{~s}^{-1}\right)$ is 

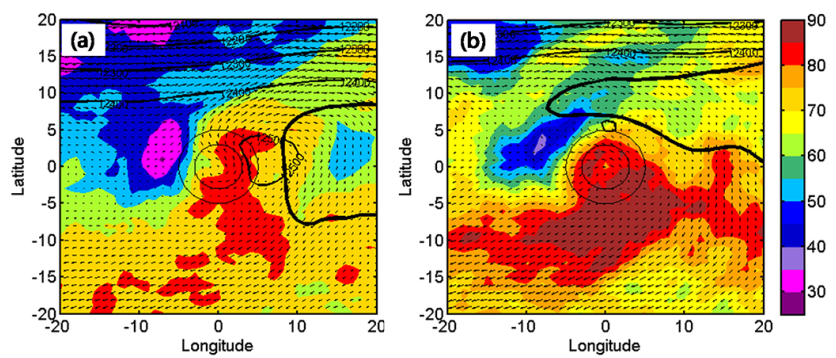

Figure 10. GFS-derived fields for the composites of vector winds, RH (shading), geopotential height (contours, $100 \mathrm{gpm}$ intervals starting at $12100 \mathrm{gpm}$ ) at $200 \mathrm{hPa}$, and geopotential height of $5880 \mathrm{~m}$ at $500 \mathrm{hPa}$ (thick black line) for (left) weakening and (right) strengthening events at time $t_{+48} \mathrm{~h}$. The two black solid circles are $3^{\circ}$ - and $5^{\circ}$-radius circles centered on the storm.

now approximately similar to that of the intensifying cases $\left(32.8 \mathrm{~m} \mathrm{~s}^{-1}\right)$ at $t_{+48 \mathrm{~h}}$.

The new composite fields in terms of VWS (magnitude and direction), CAPE (convective available potential energy), moisture and streamline for both cases are similar to those of the original composite without geographic restrictions. The averaged environmental VWS is $10.1 \mathrm{~m} \mathrm{~s}^{-1}$ in a westerly direction for the weakening cases and $8.4 \mathrm{~m} \mathrm{~s}^{-1}$ in a easterly direction for the intensifying cases. Figure 11a and b shows the respective composites of the $500 \mathrm{hPa} \mathrm{RH}$ and streamlines for both cases at $t_{+48 \mathrm{~h}}$. For the weakening cases (Fig. 11a), the westerly environmental flow brings the drier air closer to the southwestern quadrant of the inner region of the storm while it does not facilitate the transport of moist air into the eastern side of the TC. For the strengthening cases (Fig. 11b), moist air is more likely to be transported into the inner-core region of the TC, while the dry air in the west is prone to be advected outside under the influence of easterly environmental VWS. This result is consistent with the overall composite without geographic restrictions, suggesting that the dry air intrusion and the VWS associated with the WNPSH indeed affect the intensity changes of TCs over the WNP beyond the difference related solely to variations in geographical locations.

Previous studies suggested that the intruding drier air may negatively impact the intensity of TCs in the following pathways: (1) intrusion of the low-entropy air frustrates the conversion of heat into kinetic energy within the TC's power engine, as mentioned by Tang and Emanuel (2010); (2) entrainment of dry air into the convective cloud reduces buoyancy (James and Markowski, 2010); and (3) the drier and cooler air (low $\theta e$ ) could serve as "anti-fuel" for the TC power when shear-induced downward-flux low $\theta e$ air enters the inflow layer of the TC from above, especially at midlevels where mixing of low $\theta e$ air into the eyewall is thought to be particularly effective (Riemer et al., 2010, 2013). Consistent with findings from these idealized results, the current composite study with a large number of observed TCs over the WNP
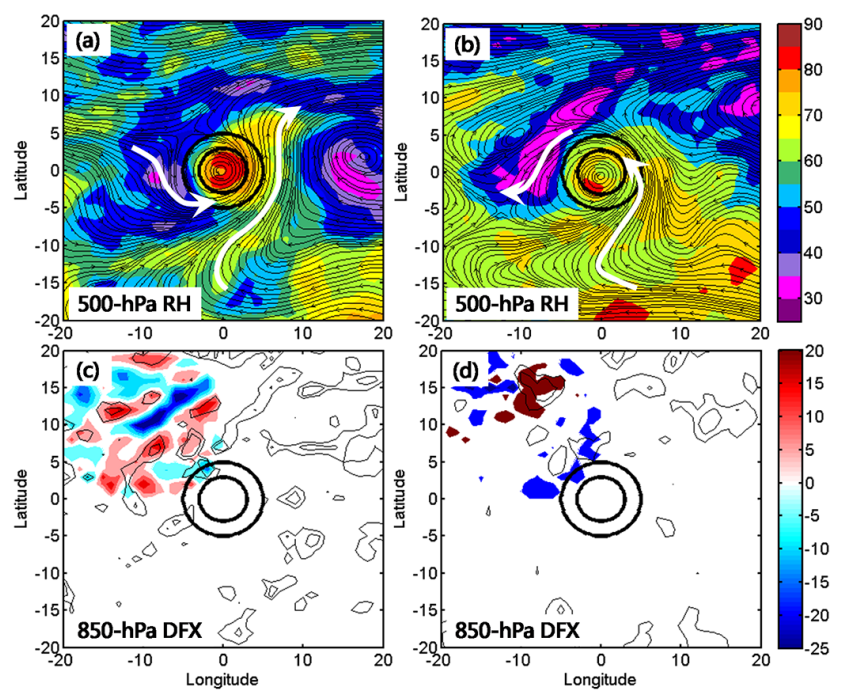

Figure 11. GFS-derived fields for the composites of RH (shading, $5 \%$ intervals starting at $25 \%$ ), streamlines at $500 \mathrm{hPa}$ (top) and DFX (shading, in $5 \mathrm{Km} \mathrm{s}^{-1}$ ), vertical velocity (contours, $-0.25 \mathrm{~m} \mathrm{~s}^{-1}$ and $-0.5 \mathrm{~m} \mathrm{~s}^{-1}$ ) at $850 \mathrm{hPa}$ (bottom) for (left) weakening and (right) strengthening events confined to the west of $135^{\circ} \mathrm{E}$ at time $t_{+48 h}$. The solid white arrows in (a) and (b) highlight the mean streamlines in the western and eastern sides of TC. Two black solid circles are $3^{\circ}$ - and $5^{\circ}$-radius circles centered on the storm.

shows that a broad area of drier air is brought into the western half of the TC circulation that lowers the relative humidity and suppresses the moisture supply. Intrusion of the dry air promotes evaporative cooling and enhances the cold downdrafts, which subsequently cools the boundary layer, reduces the CAPE (Fig. 13a), and thus suppresses the deep convective development.

The impact of dry air intrusion on TC development can also be seen clearly from the composite downward flux of $\theta e$ at the top of the boundary layer (Fig. 11c-d) as $\mathrm{DFX}=w_{-} \theta^{\prime} e$, where $w_{-}$is downward motion and the prime denotes the deviation from the azimuthal mean. The top of the boundary layer is defined roughly as the top of the axisymmetric inflow layer (set at $850 \mathrm{hPa}$ for this study). Positive values of DFX (downward flux) denote downward flux of anomalously low $\theta e$ into the inflow layer. Figure 11c and $\mathrm{d}$ shows the distributions of DFX and downdrafts for both cases. It is easily seen that positive DFX dominates the northwestern quadrant in the weakening composite in comparison with negative DFX over the same region for the intensifying cases. In addition, the descending area outside the eyewall coincides with the anomalously low $\theta e$ air brought in from the environment for the weakening cases (Fig. 11c), suggesting an amplified negative impact of dry air intrusion there. Although it remains unclear precisely how the drier air enters the eyewall updrafts and limits the strengthening of storms due to the coarser resolution of the GFS data we used, the 
(a)
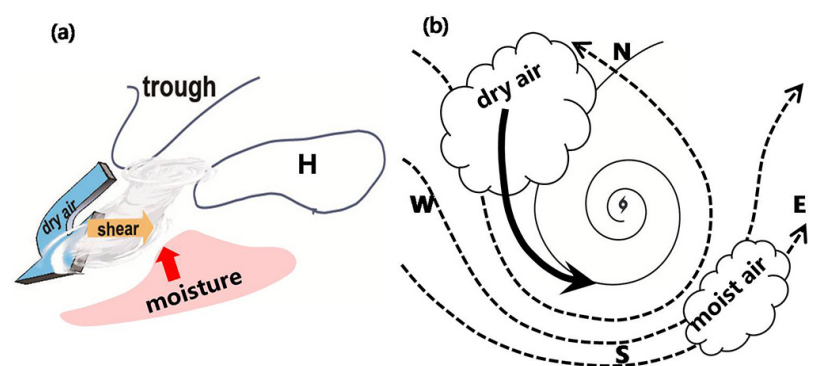

(c)

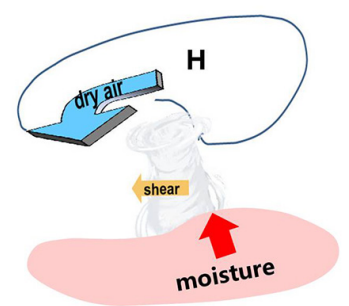

(d)

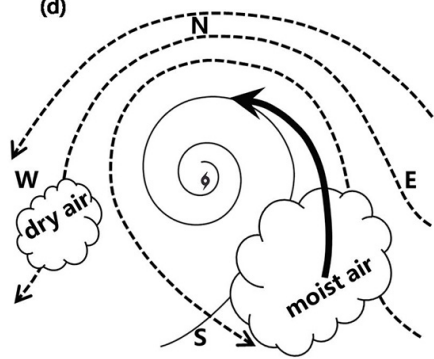

Figure 12. Schematic of the influences of the WNPSH on the intensity change of a (top) weakening and (bottom) strengthening TC. " $\mathrm{H}$ " in (a) and (c) indicates the WNPSH; in (b) and (d), the dashed curves denote the westerly and easterly storm-relative environmental flow, respectively. The solid curves roughly indicate the TC's inner-core-region boundary, and the regions of dry and moist air represent the actual areas of dry or moist air in the earlier composite results. The thick curved arrows indicate the ways the dry or moist air enters the TC circulation. (see text for details).

apparent difference of DFX between the two groups demonstrates clear links between the environmental moisture content and TC intensity, which complements recent idealized studies of Riemer et al. (2010, 2013).

Above all, the composite results clearly demonstrate that the intensity changes of TCs are closely related to the upper-level westerly trough-WNPSH-TC interaction over the WNP. Figure 12 shows the schematic of the influences of the WNPSH on the intensity changes of TCs by referring to the display methodology used by Willoughby et al. (1984, their Fig. 18) and Riemer and Montgomery (2011, their Fig. 10). When a TC moves along the western edge of the WNPSH, under the combined influences of the WNPSH and the upper-level westerly trough, the strong westerly and nearly calm wind is established in the higher and lower levels in the TC environment, respectively. The TC thus will be under the strong westerly environmental VWS, which advects the northwest, dry environmental air associated with the WNPSH (or the supplement from the upper-level westerly trough) towards the western part within the $500 \mathrm{~km}$ radius of the TC, and in the meanwhile prevents the warm, moist air from being transported into the eastern side of the TC (Fig. 12a, b).

However, when a TC moves along the southern border of the WNPSH, under the influence of the easterlies associated
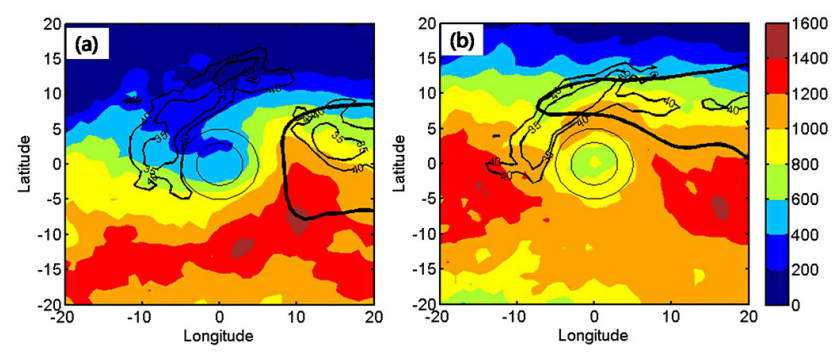

Figure 13. GFS-derived fields for the composites of CAPE (shading) and geopotential height of $5880 \mathrm{~m}$ at $500 \mathrm{hPa}$ (thick black line) for (left) weakening and (right) strengthening events at time $t_{+48 \mathrm{~h}}$. Black contours are drawn at 40 and $35 \% 500 \mathrm{hPa}$ RH. The two black solid circles are $3^{\circ}$ - and $5^{\circ}$-radius circles centered on the storm.

with the high-pressure system, the strong and weak easterly wind is established in the higher and lower levels in the TC environment, respectively. Therefore, the TC will be under the weak easterly environmental VWS, which advects the southeast warm, moist air towards the TC while preventing the dry air from intruding into the western side of the TC (Fig. 12c, d). The TC also interacts with the environmental dry air over the northern part of it, but to a lesser degree (Fig. $13 \mathrm{~b})$ in comparison with that for the weakening events. In addition, the fusion of warm, moist air from the south/southeast may lessen this detrimental impact on TC intensity (from shear or dry intrusion) and thus keep the TC intensifying. Again, the observational composites presented here complement the recent study of Riemer and Montgomery (2011), who concluded that the adverse impact of the VWS on a TC may be sensitive to the direction of the shear from their idealized simulations.

\subsection{Underlying SST}

The underlying SST should also be taken into account when analyzing the intensity changes of TCs. As shown before, the intensifying and the weakening TCs are usually located on the southern and western edges of the WNPSH, respectively. That means the central positions for the former are usually located farther southward than the latter. Table 3 shows the average SSTs and POTs (the potential intensity, which is the difference between the maximum potential intensity (MPI) and the current intensity of a TC) (DeMaria and Kaplan, 1999) for the weakening and strengthening cases at different times. The differences of SSTs between the two cases for the three instances are statistically significant at the $95 \%$ confidence level from Student's $t$ test. On average, the underlying SSTs are about 27.6 and $28.9^{\circ} \mathrm{C}$ for the weakening and strengthening cases, respectively, similar to those with additional geographic restrictions. Previous results showed that TC intensification is favorable when SST is between $27^{\circ}$ and $30^{\circ} \mathrm{C}$ (Chan et al., 2001). The average SST of $27.6^{\circ} \mathrm{C}$ for the weakening events is above the critical value of $27^{\circ} \mathrm{C}$ 


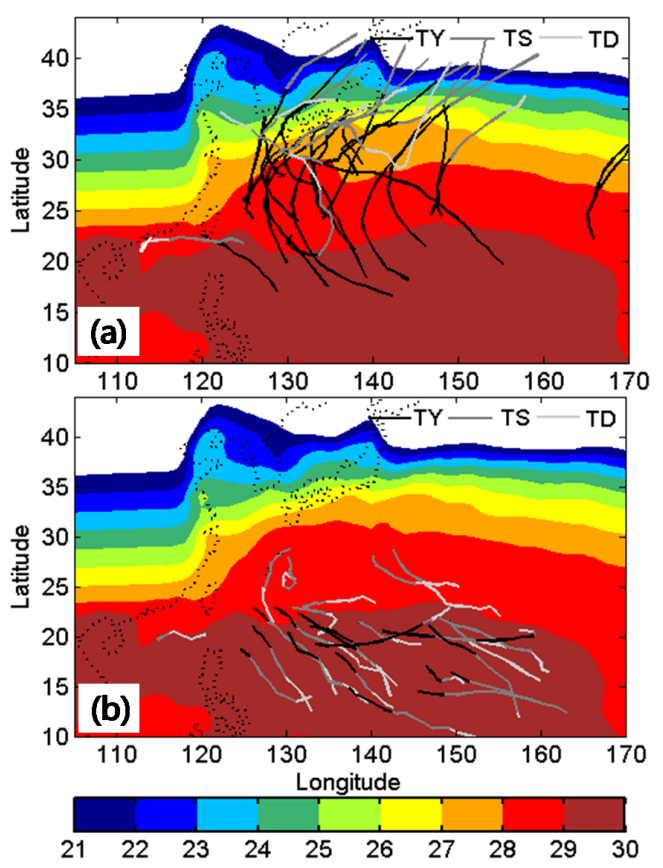

Figure 14. The average SST fields (shading) and TCs tracks (colorized lines with storm intensity) during their (a) weakening and (b) strengthening stages.

and, thus by itself, should not be the primary factor that leads to the weakening of TCs. Rather, in comparison with an average of $28.9^{\circ} \mathrm{C}$ for the strengthening events, the SST may be regarded as a less positive factor for the weakening events.

Figure 14 shows the average SST fields and all TC tracks. For the weakening stages (Fig. 14a), the TCs are usually located on the western edge of the WNPSH and tend to have northward and then recurving tracks. However, for the strengthening stages (Fig. 14b), the TCs normally move along the southern border of the WNPSH and have straight west-northwestward tracks. In other words, a westnorthwestward-moving TC over the southern border of the WNPSH is more likely to intensify, but a northward and recurving TC over the western periphery of the WNPSH is more likely to weaken. Zeng et al. (2007) also found that the recurving TCs are more likely to weaken due to their high translational speed.

Although the differences of the POTs between the two cases are also statistically significant for different times, the averaged POTs for the two groups are positive suggesting that both thermodynamic environments have the potential to support TC intensification, which further supports our hypothesis on a less positive effect of SST for the weakening cases.

\section{Concluding remarks}

The influence of environmental conditions on the intensity changes of TCs over the WNP are investigated observationally by using the satellite-derived data (AIRS-AMSU), NCEP GFS analyses and NOAA Reynolds SST reanalysis, and TC best-track estimates from JMA in this paper. A total of 37 TCs during 2000-2011 that possibly interacted with the WNPSH are examined. Based on the $48 \mathrm{~h}$ intensity changes of these TCs after they interact with the WNPSH for at least $48 \mathrm{~h}$, a comprehensive composite analysis of the environmental conditions is performed for two stages of storms: one is categorized as the intensifying events (maximum wind speed increases by $15 \mathrm{kn}$ over $48 \mathrm{~h}$ ) and the other is categorized as the weakening events (maximum wind speed decreases by $15 \mathrm{kn}$ over $48 \mathrm{~h}$ ). The characteristics of the weakening and intensifying cases are computed and compared to address how the environmental conditions play roles in the development of TCs over the WNP.

It is found that when a TC moves along the western edge of the WNPSH, under the combined influences of the WNPSH and the upper-level westerly trough, a strong westerly flow is established in the upper levels of the environment surrounding the TC but with calm low-level winds. This environmental flow of westerly vertical wind shear advects the dry air masses associated with the WNPSH (or the supplement from the upper-level westerly trough) from the north and northwest towards the western part of the TC circulation within a $500 \mathrm{~km}$ radius, and in the meanwhile prevents the warm, moist air from being transported into the eastern side of the TC. The intruding dry air resulting from subsidence negatively impacts TCs in several ways, such as lowering the relative humidity over the western half of the TC, reducing CAPE and suppressing the convective development within TCs. The change of zonal wind at $200 \mathrm{hPa}$ from weak easterly to westerly indicates the beginning of TC weakening and can be served as a good indication of the weakening of TC when it interacts with the WNPSH.

When a TC moves along the southern edge of the WNPSH, the TC is under the influence of the easterlies associated with the high-pressure system throughout the troposphere (stronger easterly above and lower below). An environmental flow of easterly vertical wind shear advects the warm, moist air from the south and southeast towards the TC while preventing the dry air from intruding into the western side of the TC. Although the environmental dry air may have also affected the TC from the north, it is to a much lesser degree in comparison with that for the weakening events. In addition, the fusion of warm, moist air from the south/southeast may lessen this detrimental impact on TC intensity (from shear or dry intrusion) and thus keep the TC intensifying.

These composite results are consistent with those with additional geographic restrictions, suggesting that the dry air intrusion and the VWS associated with the WNPSH indeed affect the intensity changes of TCs over the WNP beyond the 
Table 3. The average SSTs and POTs for the weakening and intensifying cases at different times.

\begin{tabular}{llcccc}
\hline & & $t_{0 \mathrm{~h}}$ & $t_{+24 \mathrm{~h}}$ & $t_{+48 \mathrm{~h}}$ & average \\
\hline SST $\left({ }^{\circ} \mathrm{C}\right)$ & weakening & $28.3(28.3)$ & $27.8(27.9)$ & $26.7(27.1)$ & $27.6(27.8)$ \\
& intensifying & $29.0(29.4)$ & $28.9(28.7)$ & $28.7(28.7)$ & $28.9(28.9)$ \\
\hline \multirow{2}{*}{ POT $\left(\mathrm{m} \mathrm{s}^{-1}\right)$} & weakening & $33.4(37.1)$ & $31.7(35.0)$ & $34.0(35.5)$ & $33.0(35.9)$ \\
& intensifying & $62.0(66.5)$ & $54.9(53.8)$ & $46.2(46.8)$ & $54.4(55.7)$ \\
\hline
\end{tabular}

Values in the parentheses mean the SSTs and POTs for the two groups with geographic restrictions (see text for details).

difference related solely to variations in geographical locations.

On average, a west-northwestward-moving TC over the southern border of the WNPSH is more likely to intensify, but a northward and recurving TC over the western periphery of the WNPSH is more likely to weaken. The composite SST of $27.6^{\circ} \mathrm{C}$ for the weakening events on the western edge of the WNPSH is above the critical value of $27^{\circ} \mathrm{C}$, and thus by itself, should not be the primary factor that leads to the weakening of TCs. Rather, in comparing with an average of $28.9^{\circ} \mathrm{C}$ for the strengthening events on the southern periphery of the WNPSH, the SST may be regarded as a less positive factor for the weakening of storms. The positive POT for the weakening cases further supports this inference.

The results of this study suggest that the environmental conditions influence the intensity changes of TCs in many ways over the WNP. For one who tries to forecast the intensity changes of TCs over the WNP, he or she should take into account the impacts of the WNPSH, the upper-level westerly trough as well as the underlying SSTs. The detailed physical processes such as how cooler and drier air enters the core region and inhibits the development of a TC, as well as which environmental factor dominates the intensity change of a TC will be discussed by using a numerical model in the near future.

Acknowledgements. We thank the editor (T. Dunkerton), D. Tao and two anonymous reviewers for their insightful comments on an earlier version of the manuscript. This study is supported by the project of the National (Key) Basic Research and Development (973) Program of China (2009CB421502), China Meteorological Administration Special Public Welfare Research Fund (GYHY201006007), National Natural Science Foundation of China (40905020, 41275057), State Key Laboratory of Severe Weather (2013LASW-B17), and funds for the Priority Academic Program Development (PAPD) of Jiangsu Higher Education Institutions.

Edited by: T. J. Dunkerton

\section{References}

Bender, M. A. and Ginis, I.: Real-case simulations of hurricaneocean interaction using a high-resolution coupled model: Effects on hurricane intensity, Mon. Weather Rev., 128, 917-943, 2000.

Bender, M. A., Ginis, I., and Kurihara, Y.: Numerical simulations of tropical cyclone-ocean interaction with a high resolution coupled model, J. Geophys. Res., 98, 23245-23263, 1993.

Black, P. G.: Ocean temperature changes induced by tropical cyclones, $\mathrm{Ph}$. D. dissertation, The Pennsylvania State University, Pennsylvania, 278 pp., 1983.

Braun, S. A.: Re-evaluating the role of the Saharan Air Layer in Atlantic tropical cyclogenesis and evolution, Mon. Weather Rev., 138, 2007-2037, 2010.

Byers, H. R.: General Meteorology, McGraw-Hill, 645 pp., 1944.

Cangialosi, J. P. and Franklin, J. L.: 2011 National Hurricane Center verificationreport, Trop. Predict. Cent., Natl. Hurricane Cent., Natl. Cent. for Environ. Predict.,Natl. Weather Cent., NOAA, Miami, Fla, http://origin.www.nhc.noaa.gov/ verification/pdfs/Verification_2011.pdf, (last access: 28 November 2013), 2012.

Cione, I. J. and Uhlhorn, E. W.: Sea surface temperature variability in hurricanes: Implications with respect to intensity change, Mon. Weather Rev., 131, 1783-1796, 2003.

Chan, J. C. L.: Tropical cyclone activity over the western North Pacific associated with El Niño and La Niña events, J. Climate, 13, 2960-2972, 2000.

Chan, J. C. L., Duan, Y. H., and Shay, L. K.: Tropical cyclone intensity change from a simple ocean-atmosphere coupled model, J. Atmos. Sci., 58, 154-172, 2001.

Chan, J. C. L., Ching, S. E., and Lai, Edwin, S. T.: Asymmetric distribution of convection associated with tropical cyclones making landfall along the South China coast, Mon. Weather Rev., 132, 2410-2420, 2004.

Chan, K. T. F. and Chan, J. C. L.: Size and strength of tropical cyclones as inferred from QuikSCAT data, Mon. Weather Rev., 140, 811-824, 2012.

Chen, J. M. and Chen, H. S.: Interdecadal variability of summer rainfall in Taiwan associated with tropical cyclones and monsoons, J. Climate, 24, 5786-5798, 2011.

Chen, T. C., Wang, S. Y., Yen, M. C., and Clark, A. J.: Impact of the intraseasonal variability of the Western North Pacific largescale circulation on tropical cyclone tracks, Weather Forecast., 24, 646-666, 2009

Corbosiero, K. L. and Molinari, J.: The relationship between storm motion, vertical wind shear, and convective asymmetries in tropical cyclones, J. Atmos. Sci., 60, 366-376, 2003. 
DeMaria, M. and Kaplan, J.: An updated statistical hurricane intensity prediction scheme for the Atlantic and eastern North Pacific basins, Weather Forecast., 14, 326-337, 1999.

Dunion, J. P. and Velden, C. S.: The impact of the Saharan air layer on Atlantic tropical cyclone activity, B. Am. Meteorol. Soc., 85, 353-365, 2004

Dunkerton, T. J., Montgomery, M. T., and Wang, Z.: Tropical cyclogenesis in a tropical wave critical layer: easterly waves, Atmos. Chem. Phys., 9, 5587-5646, doi:10.5194/acp-9-5587-2009, 2009.

Emanuel, K. A.: An air-sea interaction for tropical cyclones. Part I: Steady-state maintenance, J. Atmos. Sci., 43, 585-604, 1986.

Emanuel, K. A.: The maximum intensity of hurricanes, J. Atmos. Sci., 45, 1143-1155, 1988.

Emanuel, K. A.: The theory of hurricanes, Annu. Rev. Fluid Mech., 23, 179-196, 1991.

Emanuel, K. A.: Sensitivity of tropical cyclones to surface exchange coefficients and a revised steady-state model incorporating eye dynamics, J. Atmos. Sci., 52, 3969-3976, 1995.

Emanuel, K. A.: A statistical analysis of hurricane intensity, Mon. Weather Rev., 128, 1139-1152, 2000.

Emanuel, K. A., Autels, C. D., Holloway, C., and Korty, R.: Environmental control of tropical cyclone intensity, J. Atmos. Sci., 61, 843-858, 2004.

Evan, A. T., Dunion, J., Foley, J. A., Heidinger, A. K., and Velden, C. S.: New evidence for a relationship between Atlantic tropical cyclone activity and African dust outbreaks, Geophys. Res. Lett., 33, L19813, doi:10.1029/2006GL026408, 2006.

Fang, J. and Zhang, F.: Effect of Beta Shear on Simulated Tropical Cyclones, Mon. Weather Rev., 140, 3327-3346, 2012.

Frank, W. M. and Ritchie, E. A.: Effects of environmental flow upon tropical cyclone structure, Mon. Weather Rev., 127, 2044-2061, 1999.

Frank, W. M. and Ritchie, E. A.: Effects of vertical wind shear on the intensity and structure of numerically simulated hurricanes, Mon. Weather Rev., 129, 2249-2269, 2001.

Fu, B., Peng, M. S., Li, T., and Stevens, D. E.: Developing versus Nondeveloping Disturbances for Tropical Cyclone Formation. Part II: Western North Pacific, Mon. Weather Rev., 140, 10671080, 2012.

Gray, W. M.: Global view of the origin of tropical disturbances and storms. Mon. Weather Rev., 96, 669-700, 1968.

Hanley, D., Molinari, J., and Keyser, D.: A composite study of the interaction between tropical cyclones and uppertropospheric troughs, Mon. Weather Rev., 129, 2570-2584, 2001.

Harr, P. and Elsberry, R.: Large-scale circulation variability over the tropical western North Pacific. Part I: Spatial patterns and tropical cyclone characteristics, Mon. Weather Rev., 123, 12251246, 1995.

Holland, G. J.: The maximum potential intensity of tropical cyclones, J. Atmos. Sci., 54, 2519-2541, 1997.

Hong, X., Chang, S. W., Raman, S., Shay, L. K., and Hodur, R.: The interaction between Hurricane Opal (1995) and a warm core ring in the Gulf of Mexico, Mon. Weather Rev., 128, 1347-1365, 2000.

James, R. P. and Markowski, P. M.: A Numerical Investigation of the Effects of Dry Air Aloft on Deep Convection, Mon. Weather Rev., 138, 140-161, 2010.
Lander, M. A.: An exploratory analysis of the relationship between tropical storm formation in the western North Pacific and ENSO, Mon. Weather Rev., 122, 636-651, 1994.

Lau, K. M. and Kim, J. M.: How nature foiled the 2006 hurricane forecasts, EOD T. Am. Geophys. Un., 88, 105-107, doi:10.1029/2007EO090002, 2007a.

Lau, K. M. and Kim, J. M.: Cooling of the Atlantic by Saharan dust. Geophys. Res. Lett., 34, L23811, doi:10.1029/2007GL031538, $2007 b$.

Lee, C.-S., Cheung, K. K. W., Fang, W.-T., and Elsberry, R. L.: Initial maintenance of tropical cyclone size in the western North Pacific, Mon. Weather Rev., 138, 3207-3223, 2010.

Liu, K. S. and Chan, J. C. L.: Synoptic flow patterns associated with small and large tropical cyclones over the western North Pacific, Mon. Weather Rev., 130, 2134-2142, 2002.

Mainelli, M., DeMaria, M., Shay, L. K., and Goni, G.: Application of oceanic heat content estimation to operational forecasting of recent Atlantic category 5 hurricanes, Weather Forecast., 23, 316,2008

Malkus, J. S. and Riehl, H.: On the dynamics and energy transformations in steady-state hurricanes, Tellus, 12, 1-10, 1960.

McBride, J.: Tropical cyclone formation: Global Perspectives on Tropical Cyclones, World Meteorological Organization Rep. TCP-38, WMO/TD-No. 693, 63-105, 1995.

Merrill, R. T.: Environmental influences on hurricane intensification, J. Atmos. Sci., 45, 1678-1687, 1988.

Miller, B. L.: On the maximum intensity of hurricanes, J. Meteorol., 15, 184-195, 1958.

Karyampudi, V. M. and Carlson, T. N.: Analysis and numerical simulations of the Saharan air layer and its effect on easterly wave disturbances, J. Atmos. Sci., 45, 3102-3136, 1988.

Karyampudi, V. M. and Pierce, H. F.: Synoptic-scale influence of the Saharan air layer on tropical cyclogenesis over the eastern Atlantic, Mon. Weather Rev., 130, 3100-3128, 2002.

Palmén, E.: On the formation and structure of tropical hurricanes, Geophysica, 3, 26-38, 1948.

Reasor, P. D., Montgomery, M. T., and Grasso, L. D.: A new look at the problem of tropicalcyclones in vertical shear flow: Vortex resiliency, J. Atmos. Sci., 61, 3-22, 2004.

Reasor, P. D., Rogers, R., and Lorsolo, S.: Environmental Flow Impacts on Tropical Cyclone Structure Diagnosed from Airborne Doppler Radar Composites, Mon. Weather Rev., 141, 29492969, 2013.

Reynolds, R. W., Rayner, N. A., Smith, T. M., Stokes, D. C., and Wang, W.: An improved in situ and satellite SST analysis for climate, J. Climate, 15, 1609-1625, 2002.

Riemer, M. and Montgomery, M. T.: Simple kinematic models for the environmental interaction of tropical cyclones in vertical wind shear, Atmos. Chem. Phys., 11, 9395-9414, doi:10.5194/acp-11-9395-2011, 2011.

Riemer, M., Montgomery, M. T., and Nicholls, M. E.: A new paradigm for intensity modification of tropical cyclones: thermodynamic impact of vertical wind shear on the inflow layer, Atmos. Chem. Phys., 10, 3163-3188, doi:10.5194/acp-10-31632010, 2010.

Riemer, M., Montgomery, M. T., and Nicholls, M. E.: Further examination of the thermodynamic modification of the inflow layer of tropical cyclones by vertical wind shear, Atmos. Chem. Phys., 13, 327-346, doi:10.5194/acp-13-327-2013, 2013. 
Shay, L. K., Goni, G. J., and Black, P. G.: Effects of a warm oceanic feature on Hurricane Opal, Mon. Weather Rev., 128, 1366-1383, 2000.

Shu, S. and Wu, L.: Analysis of the influence of the Saharan air layer on tropical cyclone intensity using AIRS/Aqua data, Geophys. Res. Lett., 36, L09809, doi:10.1029/2009GL037634, 2009.

Shu, S., Ming, J., and Chi, P.: Large-Scale Characteristics and Probability of Rapidly Intensifying Tropical Cyclones in the Western North Pacific Basin, Weather Forecast., 27, 411-423, 2012.

Simpson, R. H. and Riehl, H.: Mid-tropospheric ventilation as aconstraint on hurricane development and maintenance, in: Proc.Tech. Conf. on Hurricanes, D4.1-D4.10, Amer. Meteorol. Soc., Miami, FL, 1958.

Stern, D. P. and Zhang, F.: How does the eye warm? Part II: Sensitivity to Vertical Wind Shear, and a Trajectory Analysis, J. Atmos. Sci., 70, 1849-1873, 2013.

Sun, D., Lau, K. M., and Kafatos, M.: Contrasting the 2007 and 2005 hurricane seasons: Evidence of possible impacts of Saharan dry air and dust on tropical cyclone activity in the Atlantic basin, Geophys. Res. Lett., 35, L15405, doi:10.1029/2008GL034529, 2008.

Sutyrin, G. G. and Khain, A. P.: Interaction of the ocean and the atmosphere in the area of moving tropical cyclone, Dokl. Akad. Nauk. SSR, 249, 467-470, 1979.

Tang, B. and Emanuel, K. A.: Midlevel ventilation's constraint on tropical cyclone intensity, J. Atmos. Sci., 67, 1817-1830, 2010.
Titley, D. W. and Elsberry, R. L.: Large intensity changes in tropical cyclones: A case study of supertyphoon Flo during TCM-90, Mon. Weather Rev., 128, 3556-3573, 2000.

Wang, Y. and Wu, C.-C.: Current understanding of tropical cyclone structure and intensity changes - A review, Meteor. Atmos. Phys., 87, 257-278, 2004.

Willoughby, H. E., Marks, F. D., and Feinberg, R. J.: Stationary and moving convective bands in hurricanes, J. Atmos. Sci., 41, 31893211, 1984.

Wu, L.: Impact of Saharan air layer on hurricane peak intensity, Geophys. Res. Lett., 34, L09802, doi:10.1029/2007GL029564, 2007.

Zeng, Z., Wang, Y., and Wu, C.-C.: Environmental Dynamical Control of Tropical Cyclone Intensity - An Observational Study, Mon. Weather Rev., 135, 38-59, 2007.

Zhang, F. and Sippel, J. A.: Effects of moist convection on hurricane predictability, J. Atmos. Sci., 66, 1944-1961, 2009.

Zhang, F. and Tao, D.: Effects of Vertical Wind Shear on the Predictability of Tropical Cyclones, J. Atmos. Sci., 70, 975-983, 2013.

Zhang, F., Weng, Y., Gamache, J. F., and Marks, F. D.: Performance of Convection-permitting Hurricane Initialization and Prediction during 2008-2010 with Ensemble Data Assimilation of Innercore Airborne Doppler Radar Observations, Geophys. Res. Lett., 38, L15810, doi:10.1029/2011GL048469, 2011. 